\title{
Safeguarding Adults and Mass Marketing Fraud - perspectives from the Police, Trading Standards and the Voluntary Sector
}

\begin{abstract}
Despite the growing awareness of Mass Marketing Fraud (MMF) in the financial abuse of vulnerable older people, little empirical research has been undertaken in this area. This paper is one of the first to consider the perspectives of a range of professionals who work with victims of mass marketing fraud and financial crime. MMF is a growing threat in the financial abuse of older people, and is increasingly recognised as a concern for professionals involved in supporting and safeguarding vulnerable older people.

This paper considers the themes emerging from a small exploratory qualitative study into the perspectives of professionals working to safeguard those at risk of MMF and considers some of the complexities involved in tackling MMF. This involves consideration of the techniques used to groom and lure victims in plausible looking frauds, and the factors which serve to reinforce their sustained involvement in such activity.
\end{abstract}

Key words: Mass marketing fraud, financial abuse, safeguarding, older people.

\section{Introduction}

The most significant reform of the adult social care system in England for more than 60 years comes into force in April 2015 following the introduction of the Care Act (2014). This replaces existing legislation and policy guidance with a single modern statute and guidance. This has significant implications for safeguarding adults and has introduced the first ever statutory safeguarding framework provided for under sections 42 - 47 and 68. Prior to the Care Act (2014) safeguarding had been a nonstatutory directive as part of the 'No Secrets' (2000) policy. The Care Act aims to modernise the protection of vulnerable adults within a clearer legal framework, and heralds a move away from a process-led culture of safeguarding to a more person centred approach (Skills for Care, 2014). Such a move sits comfortably with The Making Safeguarding Personal programme (LGA and ADASS, 2013) which promotes a person centred response based on a conversational approach with service users. 
More importantly the Care Act (2014) explicitly mentions financial abuse as a safeguarding concern and this raises the profile of an area of abuse and financial crime which until recently had received little attention. There is a growing recognition from the Police, Trading Standards and other agencies involved in safeguarding adults of the risks posed by financial crime, and more specifically mass marketing fraud (MMF), yet until recently little attention has been given to this topic. The Social Care Institute for Excellence in their report on financial crime against vulnerable adults (2011) has identified the growing problems posed by organised marketing fraud and financial scams which are often targeted at the most vulnerable in society. It is therefore important to develop understanding of the risks posed by such crime so that that agencies and practitioners are equipped with the skills and knowledge to support victims, and the older population are equipped with improved financial literacy skills to protect themselves. Although this paper specifically explores the context of safeguarding and mass marketing fraud from a UK perspective, this is a global issue and research in the USA suggests that financial loss by older victims of financial scams and fraud is estimated $\$ 2.9$ billion annually from financial fraud alone (MetLife Inc., 2011).

The aim of this paper is to consider the findings of a small exploratory qualitative study into the experiences of the Police, Trading Standards staff and social workers when supporting victims of mass marketing fraud. It highlights the challenges involved in supporting victims of such crime and offers recommendations for future education and training for the range of agencies involved in safeguarding older people.

\section{Mass Marketing Fraud}

There is currently little research which has specifically explored the threats posed by mass marketing fraud (Crosby et al. 2008), and there is no commonly accepted single definition of what constitutes a mass marketing scam, although four categories are identified in a review by Button, Lewis and Tapley (2009:8). These include

- Pretending to sell something you do not have, and taking the money.

- Supplying goods or services which are of lower quality than those paid for, or failing to supply the goods and services sought. 
- Persuading customers to buy something they do not really want through oppressive marketing techniques.

- Disguising one's identity in order to perpetrate a fraud (Verniero and Herr, 1997, cited in Muscat et al, 2002: 1).

Mass marketing fraud (MMF) and financial scamming is a nebulous area spanning different types of activity, although the Office of Fair Trading (2006) have identified key elements including the unsolicited nature of contact and offers built upon false promises. The OFT (2006:12) definition suggests that MMF is

"A misleading or deceptive business practice where you receive an unsolicited or uninvited contact (for example by e-mail, letter, phone, or ad) and false promises are made to con you out of money."

MMF is often perpetrated via the mail, email or telephone as fraudsters try to entice victims with false promises of large cash prizes or goods in exchange for upfront fees. Research by the Office of National Statistics (2013:1) suggests that the most common type of unsolicited communication is 'an invite to claim a big win in a lottery, prize draw, sweepstake or competition that had not been entered'.

The financial losses encountered are high and a report by the Office of Fair Trading (2006) suggests that 'UK consumers lose about £3.5 billion to scams each year' (OFT, 2006:9). Whilst older people and the socially isolated have been found to be particularly vulnerable to MMF and scams (OFT, 2009), they are less likely to report their involvement in financial scams or to seek recourse (Pak \& Shadel, 2011). This causes problems for those involved in safeguarding vulnerable adults as individuals may not wish to approach agencies for support or even admit that they have been the victim of a scam.

It is important to acknowledge that alongside financial scams perpetuated by gangs, older people often become victims of unethical sales practices by companies selling a range of products (DeLiema et al. 2014). This area of unethical sales practice may pose an increase threat in the future due to significant reforms of the pension taxation framework. The changes to pension access in April 2015 are the most significant change since the 1986 Social Security Act, and introduce flexibility in how individuals access their pensions. This raises the spectre of unscrupulous individuals and companies targeting pensioners in order to exploit this rich source of income. 
Concern has been expressed by Age UK (2014) that these pension changes may leave older people at risk of financial scams and the risk of losing money needed for retirement. This highlights the importance of agencies working with older people to develop increased awareness and responsiveness to the challenges posed by mass marketing fraud and other financial scams targeting older people.

\section{Older people and MMF}

It is difficult to determine whether specific groups are more at risk from MMF (Button et al. 2009) but research suggests that a number of factors associated with ageing may increase the risk of being both targeted and being susceptible to financial fraud. James et al. (2014) found that old age, lower levels of cognitive function, decreased psychological well-being, and lower literacy in particular may be markers of susceptibility to financial victimization in old age. Similar findings have been found in a study by Gamble et al. (2014) who found that reduced cognitive ability is associated with higher scam susceptibility scores and is predictive of fraud victimization.

Vulnerability to scams has been linked to overconfidence in one's financial knowledge and factors such as gullibility and scepticism (Langenderfer and Shimp, 2001). The notion of financial literacy may be useful to explore how individuals make informed decisions concerning their financial choices. This might include the type of information they access, their awareness of financial scams, and their willingness to seek support from professionals if they are concerned about a potential financial scam. A number of authors suggest that older people have reduced levels of financial literacy and understanding (Atkinson et al. 2006; Lusardi 2009), and in turn, lower levels of financial literacy may be linked to other vulnerability factors such as a willingness to take financial risks and trust in the plausibility of the scam (Modic 2012; Fischer et al. 2013).

It is becoming increasingly recognised that older people should be offered opportunities to make wise and informed financial decisions. For example the Financial Conduct Authority (2014) has produced guidelines to support individuals to become 'scamsmart'. This includes advice about rejecting cold calls, checking the FCA Warning List, and accessing independent financial advice in terms of 
investments. Empowering older people to protect themselves from MMF and scams may be an important approach for practitioners, particularly as experience of MMF may lead to negative psychological impacts on emotional and psychological wellbeing (Whitty and Buchanan 2012; Button, 2009). Some individuals experiencing MMF have reported stress, anxiety and loss of self-esteem (OFT, 2006). Such experiences can lead to self-blame which can further undermine individual financial capability (Button et al.2009), and can result in the victim feeling 'complicit in their victimization (Deevy, Lucich and Beal, 2012:12).

This type of research suggests that individual vulnerabilities for involvement in MMF are complex. It is therefore important that those involved in safeguarding older people develop increased understanding of these vulnerability factors, alongside an appreciation of the difficulties individuals encounter in either avoiding involvement and escaping from involvement in financial scams.

\section{Methodology}

This study was exploratory in nature and sought to gain an insight into the impact of mass marketing fraud on older people. This sample was small and a purposive qualitative sampling strategy (Patton, 1990) was used to identify participants as 'qualitative inquiry typically focuses in depth on relatively small samples, even single cases, selected purposefully' (p. 169). The sample size was necessarily small due to resource and time limitations. The overall sample comprised of three cases referred to Social Work and Trading Standards teams as a result of MMF $(n=3)$, and four professionals from different agencies who work with cases of MMF $(n=4)$. This paper reports specifically on the interviews with professional staff $(n=4)$. Inclusion criteria were that participants were either victims of MMF or were practitioners who worked with victims of MMF.

Two of the researchers work in teams which have statutory responsibility to respond to reports of financial abuse through MMF in one local authority in the SE of England, and participants were recruited via local contacts. This may have led to potential influence from the researchers due to their inside knowledge of the practice area (Fontana and Frey, 2008). Due to this 'insider' perspective the research team 
were aware of the need to remain critically reflexive throughout the research process (redacted for review).

The professionals involved represent a range of different agency roles involved in supporting victims of MMF.

The study gained ethical approval through the local authority research governance process. Participants gave written permission to take part in the study, and all names have been anonymised. In depth semi structured interviews were used to collect data, and these were recorded and transcribed by the researchers. A thematic analysis of the data was undertaken by the research team (Miles and Huberman, 1994).

\section{Findings}

A number of themes have emerged following the interviews with respondents working with victims of mass marketing fraud (MMF). These themes identify a number of reasons why people become involved in MMF scams, how this behaviour becomes sustained over a period of time, and why victims are often reluctant to stop engaging with MMF activity.

\section{Becoming involved in mass marketing fraud}

Three key areas linked to MMF are fraudster manipulation, scams appearing legitimate, and personal motivations to access money.

\section{Fraudster manipulation}

Fraudsters may manipulate interactions with older people through a variety of means to initiate them into the scamming practice. A respondent working with a voluntary sector agency with older people reported that some clients never intend to get involved but they simply answer the phone to a scam and their polite interaction is often enough for fraudsters to gain information or begin to form a relationship and manipulate the situation. Fraudsters may try to 'ingratiate themselves' to the potential victims at the point of first contact. As a result they

'Try to identify aspects of their (victim's) life that you (fraudster) can use to leverage... do they have aspirations for their children? Do they want a bigger 
house... and then you (fraudster) basically use this as leverage to say, if you do this, you get that' (Respondent from the Police Service)

Some victims are particularly vulnerable following a traumatic event. This may be a transient vulnerability due to a stressful situation or a more permanent vulnerability due to a significant life change or loss. Those victims who may have suffered bereavement may be particularly vulnerable to clairvoyant scams. These are particularly hard to stop as they can tap into emotive areas for the victim such as promising to 'contact a loved one who has passed away' (Respondent from National Scams Team). These types of approaches therefore exploit an emotional vulnerability in the victim.

Gifts are often used as a lure to entice victims initially into a scam, and a respondent from Trading Standards suggested that 'a lot of the stuff (fraud letters) is included in various types of cakes, pills all this type of thing'. The free gift in this instance acts as bait to entice the victim into the scam. In this process hooks and lures are an important part of the fraudster's toolkit.

Alternatively details of the victim may be sold onto fraudsters after an initial contact with a legitimate company. For example, respondents from the Police suggest that companies to whom an individual applies for a loan can sell information of applicants to other parties. Such licensed loan brokers can then use information about the potential victims to a fraudster. Thus a fraudster has a distinct understanding that the potential victim is looking for money and this can then be exploited.

'Scams are based on marketing principals. A response guarantees further contact from fraudsters (Respondent from the Police)

Once a scam is running, fraudsters can manipulate continuation of a fraud through threats to the individual or that something nasty might happen to their family. The respondents in this study believed that older people may be particularly vulnerable to fraudster manipulation as they are more trusting than younger people, and as a result easier to manipulate. As one respondent described 
'we have a generation who are very trusting, very willing to pay a small fee to win something big...just naturally trusting' (Respondent from the National Scams Team)

\section{Scams appear legitimate}

Individuals may initially get involved in financial scams as the letters/contacts from scammers appear legitimate and do not appear suspicious. An appearance of legitimacy then enables the victim to 'trust' the scam. Respondents from the Police suggest that this appearance of legitimacy is reinforced by delivery through the Royal Mail system. Legitimacy is also reinforced by the depiction of the victim as a 'winner' and by the formal letterheads used. Often the letter states:

"You are a winner and all you have to do is send off a one-time processing fee, people believe it and I'm sure that a lot of people actually don't think it's fraud." (Respondent from the Police)

Legitimate looking mail may contain 'hidden scams' as the terms and conditions that are often written in small font and in a grey colour making it very difficult to read even for older people with good eyesight. Even those who try to read the small print to objectively evaluate the mail may well be unable to read it fully. Therefore the professional marketing techniques used and the presentation of offers to make them appear genuine is another key tool in the fraudsters toolkit.

\section{Personal motivations to access money}

Victims of MMF often view the scam as a legitimate way of winning money for themselves or their wider family. For example, agencies working with MMF report that victims have spoken of their wish to win the money promised in the scam mail to leave as an inheritance or altruistically to give to others in their family.

"More often than not in my experience, when you speak to victims and ask them why they wanted the money quite often it's not actually for themselves, it's an aspiration that they might be able to share it with others or that it might form part of their estate if they pass away". (Respondent from the Police) Therefore altruism, or a desire to alleviate one's own poverty may be a motivating factor as to why some individuals get involved with MMF. Older people are 
particularly vulnerable to economic fluctuations due to fixed incomes and assets which are reducing in value, and the opportunity for financial gain offered through MMF offers a tempting way to boost dwindling retirement income. Unfortunately these individuals often do not have a lot of capital to lose in the first place.

\section{Factors sustaining scam behaviour}

A number of factors which sustain scam behaviour are identified by practitioners working with MMF victims. These factors are linked to individual vulnerability, a need for purposeful activity, and scam morphing.

\section{Loneliness/social isolation}

Loneliness and social isolation can make some older people vulnerable to financial scamming, and a respondent working with older people in the voluntary sector suggested that 'social isolation is definitely a key criterion across the board'. The attention paid by fraudsters can make individuals feel special as though they are personally being reached out to. Such contact becomes socially validating for the lonely, and the receipt of scamming mail becomes more socially meaningful. The social validation that comes through such contact via mail and phone offers a lifeline to lonely individuals.

'They offer a glimmer of hope that something might change (Respondent from the Voluntary Sector)

The social meaning attached to such contact has a major impact upon how the victim makes sense of the interaction as their judgement is shaped by an emotional response, rather than a logical one. The invisibility of older people within contemporary society compounds this issue, and some respondents suggest that scams are often 'unseen' as some older people have no-one else around them on a day to day basis to observe their interactions with fraudsters.

The small sums being asked for may appear inconsequential to the older person, who is getting some positive social validation through their interaction with the scam. One respondent suggested that the small loss is often a price worth paying for social contact in a sea of loneliness. 
'The small sum is worth losing' (Respondent from the Voluntary Sector).

However, as the scam develops and the sums grow bigger the older person ends up chasing the loss. Some respondents describe the social validation from such interactions as being akin to the notion of 'paying for utility'. This links to the notion of social exchange theory (Thibaut \& Kelley, 1959), where the pay offs from social interactions may result in a patterning of behaviour. Vulnerability factors linked to loneliness and social isolation, can make some individuals more susceptible to such patterns of behaviour.

'I can only assume that these people gain utility from the interaction, which kind of takes you back to the issue of social isolation' (respondent from the National Fraud Bureau).

Some individuals can become socially reliant on the relationship with the fraudster who represents a significant relationship in their lives. This can result in victims wanting to maintain contact with those that have defrauded them, even when the crime is pointed out to them by safeguarding professionals. One respondent from the Police described how a victim contacted the Police to try to resume contact with the fraudster.

'She wanted to "get in touch" because he had developed an emotional relationship with her over the phone in an attempt to get money and she missed it" (Respondent from the Police).

\section{Need for purposeful activity}

For older individuals who may be lonely and socially isolated, involvement in MMF often gives a sense of purpose and structure to their life. The range of activities involved, including contact with the fraudster, accessing money, filling in envelopes, and visiting banks represent a wide range of activities and eventually becomes a mechanism for time management. Involvement with MMF therefore 'gives the victim something to do, some purpose, some structure...I think it gives them (victims) something to do as well, you have all these boxes to fill out...going down to the post office, getting stamps, cheque books, postal orders, sending mail 
off, ...it's a big part of their day, waiting for a postman to come around' (Respondent from the Police).

The need for engagement in purposeful activity, and the buzz associated with it, was likened by one respondent as being similar to an addiction, like shopping when in debt.

'You know that debt is wrong but the buzz you get from shopping fills the gap in your life temporarily...then you go do it again (after feeling silly, guilty and stupid)" (Respondent from the Voluntary Sector).

However, the likening of on-going involvement in scam activity to addictive behaviour was seen as unhelpful by other professionals, and draws attention away from the wider social issues which underpin older people's vulnerability to scams due to loneliness and isolation.

'It may create the perception that MMF victims are in the same category as those addicted to substances' (Respondent from the Police).

It may be better to see on-going activity as a diversion away from aspects of daily life which are often defined by loneliness, isolation and a sense of futility.

\section{Scam morphing}

Individuals may stay involved in scams as the scam morphs in nature, using different lures or enticements as the initial scam wears thin. The purpose of this is to keep the victim interested so that the fraudster can try to extrapolate more money from the victim. Such scam morphing has also been described as 'fraud recovery' where the scammers change their fraud when the victim starts to challenge the initial scam, and add urgency to the demand. Urgency is designed to create and increase the probability that the person will commit an error of judgment. One respondent describes how 'scammers will create new scenarios if they feel that the victim may stop providing money' (Respondent from the Voluntary sector). Another tactic used by fraudsters is to introduce an element of exclusivity and importance into the scam, with the aim of making the individual feel special. One respondent described a victim who 'believed that she was making investments with 
the Attorney General of another country. She thought...she'd been chosen' (Respondent from the Police).

Scam morphing may make the individual believe that they owe money, and older people may be particularly susceptible to scams which require debts to be paid off quickly. Fraudsters often target older people using the language of 'debt', and this can be very powerful to older people who tend to be debt averse.

'Older people have a polite and diligent approach to paying money 'owed' that leads to the beginning of a routine of requests by the fraudster ' (Financial Advocate, Voluntary Sector).

This type of scam morphing exploits the tendency of older people to be debt averse, and highlights how fraudsters manipulate the vulnerabilities of certain population groups to their own advantage.

\section{Reluctance to end scam involvement}

Due to the relationship of trust that is nurtured by the fraudster, and the sense of utility the relationship provides, it is often easier for the victim to continue their involvement with the fraud rather than end it. Agencies involved in safeguarding adults therefore encounter problems in trying to engage victims to cease involvement, or indeed persuade them of the nature of the fraud. Agencies involved with safeguarding adults often present the victim with evidence of the financial scam and this is not easy to accept. Ending involvement in a scam therefore

'represents the finality of giving up hope of recovering losses and giving up hope of ever accessing the originally promised winnings' (Financial Advocate from the Voluntary Sector).

Many individuals therefore continue their involvement as they do not recognize their own victimhood. Others prefer to remain in denial about the scam as it means that they do not have to confront their own failings. This is summed up by one respondent who suggests that 
'Actually making those admissions to yourself and to others around you becomes much more difficult, therefore... you do get victims who would rather carry on with their pattern of behaviour rather than face up to the facts that are potentially starring them in the face' (Respondent from the Police).

Interventions from safeguarding professionals who try to dissuade continuance in the scam are often met with anger from victims who feel offended by outside intervention. The presence of the professional forces the victim to confront the scam as opposed to denying it further. Although third parties and professionals working in the fraud sector play a major role in helping people recognise their involvement in MMF, this is often a complex relationship, and one that is often rebuked. Some victims blame those trying to offer a safeguarding response with contributing to their loss of money by interfering with the scam. As a result ' they seek to apportion blame on the Police and authorities on the basis that they caused it (the scam) to fail through their intervention' (Respondent from the Police).

Victims of MMF are often deemed to have mental capacity but their judgement is impaired by their total belief in the scam despite efforts by authorities to convince otherwise. Some respondents identified weaknesses in the way in which the Mental Capacity Act (2005) is currently used and interpreted within MMF practice. This is summed up by one respondent who suggests that 'there is a gap, particularly in financial crime, with the whole issue of capacity' (Respondent from the Police).

This suggests that less consideration is given to the impact of 'undue influence' and harassment on vulnerable older people's judgement and capacity in situations of MMF. This can complicate attempts to safeguard individuals who may continue to deny there is a problem, or continue in scamming activity behind the backs of professionals who are trying to safeguard them. 


\section{Discussion}

The first ever statutory safeguarding framework has been introduced in England as part of the Care Act (2014), and a key aspect of this change is the recognition of financial abuse as a safeguarding concern. However, due to the limited research and knowledge base in relation to financial crime (Crosby et al. 2008), it is important to consider factors which may prevent professionals effectively safeguarding those at risk of MMF. This includes the interplay of complex psycho-social issues which may make older people more vulnerable to MMF, and factors which may prevent them reporting MMF to the relevant authorities or believing the nature of the scam which has taken place.

The issues emerging from this small scale study confirm the complexities involved in older people's sustained involvement with MMF. The views expressed by professionals support the findings of previous research which highlight that older people may be vulnerable to MMF due to cognitive factors (James et al. 2014), poor financial literacy (Atkinson et al. 2006; Lusardi 2009, and social isolation (OFT, 2009). Safeguarding those at risk of MMF can be a challenging area of practice as older people are less likely to report their involvement in financial scams or to seek recourse (Pak \& Shadel, 2011). They may also view Police or Trading Standards intervention as a barrier to accessing a promised prize or windfall.

A key aspect of working in this area involves how MMF is raised as an issue for older people, and how best to share information about the risks involved. Professionals need to consider how to empower older people to make wise and informed financial decisions (FCA, 2014). Such an approach should be mindful of adopting a person centred approach (Skills for Care, 2014), and one that involves a conversational approach about safeguarding concerns. This would sit comfortably with the 'Making Safeguarding Personal' approach now being developed across local authorities in England (LGA and ADASS ,2013).

As this study suggests that older people are often not receptive to approaches directly from professionals, it might be better to consider ways of raising the profile of the topic via local networks and initiatives for older people. For example social groups with an emphasis on developing financial literacy and awareness (redacted 
for review) and national conscious raising schemes such as 'scamsmart' (FSA,2014). Such approaches might have the added benefit of providing social contact, thus reducing the vulnerabilities linked to loneliness and social isolation. Opportunities for older people to share their experiences may also mitigate against the hidden and secret nature of scams, increasing their visibility and raising awareness of the risks posed by MMF.

It is important to work with older people themselves to improve their understanding of the risks posed by scams, particularly as professionals in this study felt that as a group older people are at increased risk due to their trusting natures. Criminal gangs, as well as unscrupulous businesses (DeLiema et al. 2014), may seek to exploit this 'trusting' trait in the older population in the future as new opportunities for exploitation open up due to changes in the pension system (Age UK, 2014). These changes may leave older people at increased risk of financial scams, and professionals involved in safeguarding need to be increasingly alert and responsive to the potential growth in this type of financial crime.

\section{Limitations}

The findings of this paper are limited due to the small number of participants involved. Although the small exploratory nature of the project limits the generalisations which can be made, the emerging themes have resonance with other international research on the topic. Future research should be undertaken with a larger samples of both victims of MMF and professionals involved in safeguarding older people from financial abuse and crime to develop further understanding of this complex topic.

\section{Conclusion}

This paper has offered an insight into the perspectives of professionals working with victims of MMF, and highlights some of the complexities involved in supporting victims and the reasons why some individuals sustain involvement. This can be a challenging area of practice, particularly when professional advice is rejected in favour of continuing involvement with a scam.

Professionals need to develop a deeper insight into some of the psycho-social issues which act to increase older people's vulnerability to scams including their 
financial literacy skills, loneliness, trusting natures, and quest for meaningful activity. A more concerted integrated plan of activity is required by all agencies working to safeguard older people from financial abuse and crime, and this includes exploring new and creative ways of getting the message across about MMF in a way that is meaningful and inclusive for all older people. Professional education is also be required to ensure that all professionals working with older people, including GPs, District Nurses, Social Workers, Housing and the Voluntary Sector have increased awareness of MMF and the signs that it might be happening.

\section{Acknowledgement}

The researchers wish to thank all the respondents who shared their experiences for this project. The work was supported by a research grant from the Borough of Croydon

\section{References}

Age UK (2014) Dashboards and jam-jars Helping consumers with small Defined Contribution pension pots make decisions about retirement income, available from http://www.ageuk.org.uk/Documents/EN-GB/For-professionals/Policy/moneymatters/dashboards and jamjars helping modest savers December 2014.pdf?dtr $\mathrm{k}=$ true $[$ Accessed 17/03/15]

Atkinson A, McKay S, Kempson E, and Collard, S. (2006) Levels of Financial Capability In the UK: results of a Baseline Study. Bristol: Personal Finance Research Centre, University of Bristol and FSA.

Button, M., Lewis,C., and Tapley, J. (2009)Fraud typologies and victims of fraud: Literature review, National Fraud Authority

Crosby, G., Clark, A., Hayes, R., Jones, K., and Lievesley, N. (2008)The Financial Abuse of Older People: A review from the literature carried out by the Centre for Policy on Ageing on behalf of Help the Aged, London: Help The Aged

DeLiema, M, Yongjie Y, and Wilber, K.H (2014). "Tricks of the Trade: Motivating Sales Agents to Con Older Adults." The Gerontologist doi: 10.1093/geront/gnu039 
Deevy, M., Lucich, S., and Beals, M (2012), Scams, Schemes and Swindles: A review of consumer financial fraud, Financial Fraud Research Centre, Stanford, CA.

Gamble, K.J., Boyle, P, Lei Y, and Bennett, D. (2014) The causes and consequences of financial fraud among older Americans, Centre for Retirement Research: Boston College CRR WP 2014-13 Available from: http://crr.bc.edu/wpcontent/uploads/2014/11/wp 2014-13.pdf [Accessed 12/03/15]

Financial Conduct Authority (FCA) (2014) Be a ScamSmart investor, Available online http://scamsmart.fca.org.uk/page/be-a-scamsmart-investor [accessed 17/03/15]

Fischer, P., Lea, S. E., and Evans, K. M. (2013), Why do individuals respond to fraudulent scam communications and lose money? The psychological determinants of scam compliance, Journal of Applied Social Psychology, Vol. 43 No.10 pp. 20602072.

Fontana, A., and Frey, J.H. (2008) The interview: From the neutral stance to political involvement. In N.K. Denzin and Y.S. Lincoln (Eds.), Collecting and interpreting qualitative materials (pp.115-159). London: Sage Publications Ltd.

James, B.J., Boyle, P.A., and Bennett, D.A., (2014) Correlates of Susceptibility to Scams in Older Adults Without Dementia, Journal of Elder Abuse and Neglect, 26(2)107-122

Langenderfer, J. and Shimp, T.A. (2001), Consumer Vulnerability to Scams, Swindles, and Fraud: A New Theory of Visceral Influences on Persuasion, Psychology and Marketing, Vol. 18 No. 7 pp.763-783.

Local Government Association and /Association of Directors of Adult Social Services (2014) Making Safeguarding Personal 2013-14: Report of Findings, London: LGA 
MetLife Inc. (2011) Elder Financial Abuse: Crimes of Occasion, Desperation, and Predation Against America's Elders, New York: Mature Market Institute

Miles, M.B. and Huberman A.M (1994), Qualitative data analysis: An expanded sourcebook ( $2^{\text {nd }}$ Edition), Sage, Thousand Oaks.

Modic, D. (2012), Willing to be scammed: how self-control impacts internetscam compliance, $\mathrm{PhD}$ Thesis, University of Exeter, Available from:

https://ore.exeter.ac.uk/repository/bitstream/handle/10871/8044/ModicD.pdf?sequen ce=2 [accessed 19/03/15].

Muscat, G., James, M., and Graycar, A. (2002) Older People and Consumer Fraud, No. 220, Canberra: Australian Institute of Criminology

Office of Fair Trading (2006) Research on Impact of Mass Marketed Scams, London: Office of Fair Trading.

Office of Fair Trading (2009) The Psychology of scams: Provoking and committing errors of judgement, Prepared for the Office of Fair Trading by the University of Exeter School of Psychology.

Office for National Statistics (ONS) (2013) Chapter 4: Mass Marketing Fraud, London HMSO

Available from http://www.ons.gov.uk/ons/dcp171776 309772.pdf [accessed 10/11/14]

Pak, K., \& Shadel, D. (2011, March). AARP Foundation national fraud victim study. Washington, DC: AARP Foundation National. Retrieved from http://www.aarp.org/money/scamsfraud/info-03-2011/fraud-victims-11.htm

Patton M.Q. (1990), Qualitative Evaluation and Research Methods 2nd edn. Sage, Newbury Park, California.

Skills for Care ( 2014) Briefing: Care Act implications for safeguarding adults, Available from: http://www.skillsforcare.org.uk/Document-library/Standards/Care- 
Act/learning-and-development/care-act-implications-for-safeguarding-adultsbriefing.pdf [Accessed 17/03/15]

Social Care Institute of Excellence (SCIE) (2011), Assessment: Financial crime against vulnerable adults, SCIE Report 49, SCIE, London.

Social Security Act (1986) London: HMSO

The Care Act (2014) London: HMSO

Whitty, M. and Buchanan, T. (2012) The psychology of the online dating romance scam, University of Leicester: UK. 